\title{
BRIEF COMMUNICATION OPEN Bio-artificial pleura using an autologous dermal fibroblast sheet
}

\author{
Masato Kanzaki ${ }^{1}$, Ryo Takagi ${ }^{2}$, Kaoru Washio $^{2}$, Mami Kokubo $^{2}$ and Masayuki Yamato ${ }^{2}$
}

Air leaks (ALs) are observed after pulmonary resections, and without proper treatment, can produce severe complications. AL prevention is a critical objective for managing patients after pulmonary resection. This study applied autologous dermal fibroblast sheets (DFS) to close ALs. For sealing ALs in a 44-year-old male human patient with multiple bullae, a $5 \times 15$-mm section of skin was surgically excised. From this skin specimen, primary dermal fibroblasts were isolated and cultured for 4 weeks to produce DFSs that were harvested after a 10-day culture. ALs were completely sealed using surgical placement of these autologous DFSs. DFS were found to be a durable long-term AL sealant, exhibiting requisite flexibility, elasticity, durability, biocompatibility, and usability, resulting reliable AL closure. DFS should prove to be an extremely useful tissue-engineered pleura substitute.

npj Regenerative Medicine (2017)2:26; doi:10.1038/s41536-017-0031-2

Air leaks (ALs) are frequently observed after pulmonary resections, especially video-assisted thoracoscopic surgeries (VATS). While often non-life-threatening, without proper treatment, ALs can progress to more severe complications. ${ }^{1,2}$ Based on the STS National Database (General Thoracic Surgery Database), Attaar et al. reported an incidence rate of prolonged air leak (PAL) of $8.6 \% .^{3}$ Furthermore, patients with PALs have significantly prolonged median lengths of hospital stays with the higher rates of in-hospital mortality.

The authors previously reported a novel method of cell-sheet engineering of lung $A L$ sealants using DFSs harvested from temperature-responsive culture dishes (TCDs). ${ }^{4,5}$ This study demonstrates the first known application of autologous DFS for closing a human pleural defect.

A 44-year-old male Japanese patient presenting with left chest pain and shortness of breath upon exercise over the preceding month was referred to the authors' hospital with an infected bulla. Chest computed tomography (CT) revealed multiple bullae in his left upper lobe, and one of these bullae contained fluid (Fig. 1a). A $5 \times 15-\mathrm{mm}$ surgical skin excision harvested from the anticipated surgical incision site (Fig. 1b) was used to source primary human dermal fibroblasts were cultured on tissue-culture dishes for 4 weeks (Fig. 1c). Then, cultureexpanded fibroblasts were seeded onto $35-\mathrm{mm}$ TCDs, and confluent DFSs were harvested without enzyme treatment after a 10-day culture (Fig. 1d). On the day prior to surgery, freshly prepared DFSs were subjected to various quality assessments, including sterility, mycoplasma, and endotoxin tests. Simultaneously, DFSs were cultured for investigating the number, viability, and purity of cells by measuring vimentin-positive-cell rate by flow cytometry, and DFSs found to contain $99.8 \%$ human fibroblasts. The patient underwent VATS bullectomy with a stapler. AL from the resection stump was confirmed by observing air bubbles upon submergence with saline. All ALs were completely sealed using autologous DFSs, and a water seal test confirmed stable $\mathrm{AL}$ closure against up to $25 \mathrm{~cm} \mathrm{H} \mathrm{H}_{2} \mathrm{O}$ (Fig. $1 \mathrm{e})$. Using a digital drainage system, no $\mathrm{AL}$ was detected after surgery. The postoperative course was uncomplicated. CT at one month post-surgery revealed no air space (Fig. 1f). No event was observed for 7 months after surgery, and the patient was found to be in a healthy condition.

The methods were performed in accordance with relevant guidelines and regulations and approved by the ethics committee at Tokyo Women's Medical University and by the Institutional Review Board for Clinical Research at Osaka University. Oral and written informed consents were obtained from the patient. This study was performed according to the Guidelines on clinical research using human stem cells established by the Ministry of Health, Labour, and Welfare, Japan, and registered with the University hospital Medical Information Network (UMIN) Clinical Trials Registry as No. UMIN000022554.

PALs after lung resection have negative consequences on overall morbidity, cost, and hospitalization. Intraoperative ALs should be avoided using careful surgical techniques. Various methods are currently applied to intraoperative AL closure. Especially, fibrin glue (FG)-based techniques with FG with sheet materials are preferred to close AL in Japan. However, due to the inflexibility of materials, FG-techniques give unsuccessful results. For treating recurred PALs, pleurodesis is performed with antibiotic, etc. Having various extracellular-matrix proteins, fibroblast sheets adhere to the pleural surface and close postoperative AL. Autologous DFS was used as a durable longterm $A L$ sealant that was flexible enough to move responding to the dynamic movement of lung during respiration. This study validated the efficacy of DFS as bio-artificial pleura, which sealed AL.

\footnotetext{
${ }^{1}$ The Department of Surgery I, Tokyo Women's Medical University, Tokyo, Japan and ${ }^{2}$ Institute of Advanced Biomedical Engineering and Science, Tokyo Women's Medical University, Tokyo, Japan

Correspondence: Masato Kanzaki (kanzaki@twmu.ac.jps)
}

Received: 3 March 2017 Revised: 23 August 2017 Accepted: 31 August 2017

Published online: 11 October 2017 


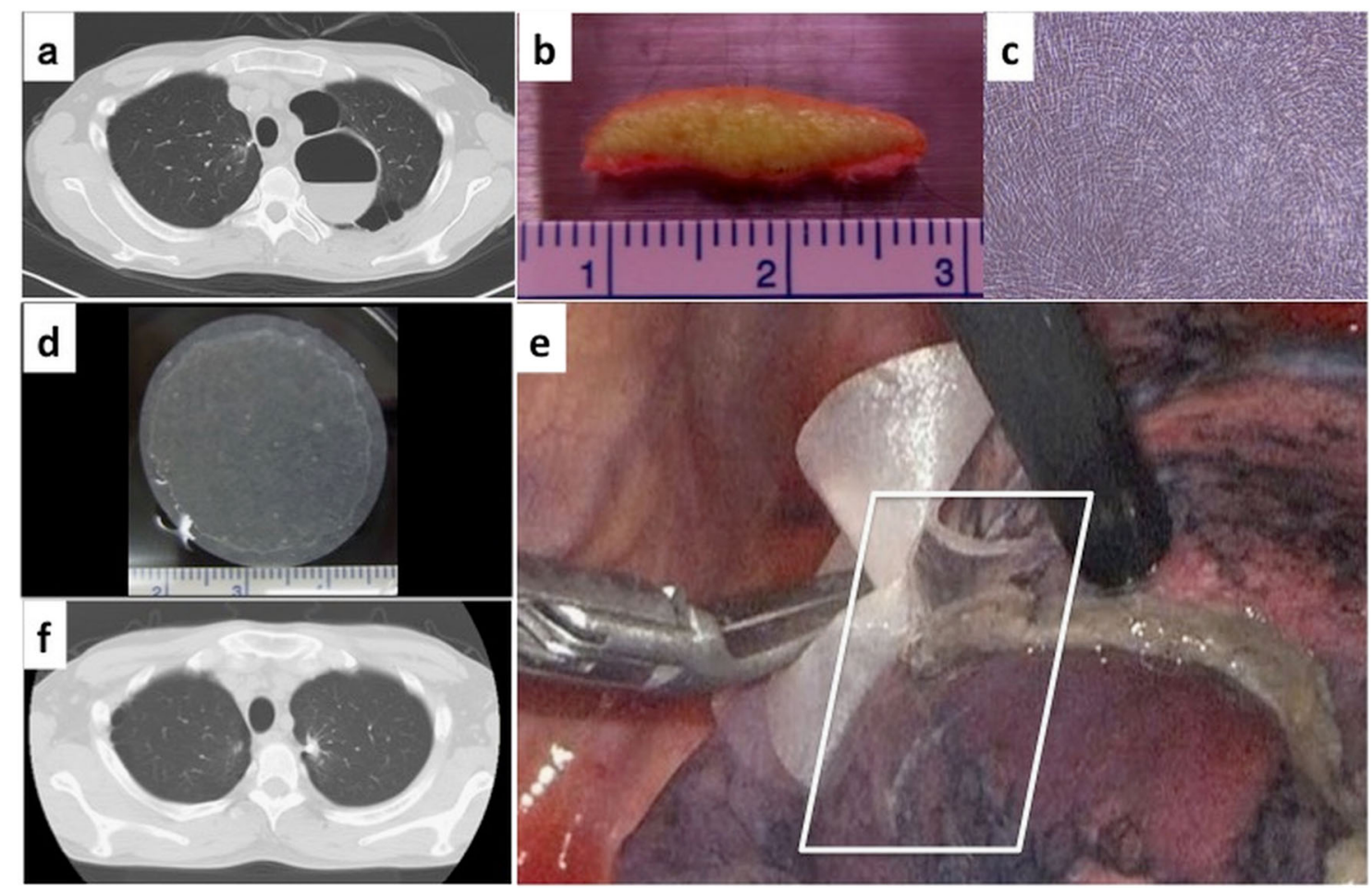

Fig. 1 a Chest CT revealed multiple bullae in patient's left upper lobe. b A $5 \times 15-\mathrm{mm}$ piece of patient skin was surgically excised from the planned surgical location of the dermal incision for the surgical repair. c Phase contrast micrograph of autologous primary dermal fibroblasts cultured for 4 weeks. d Transplantable dermal fibroblast sheet (DFS) harvested after 10-day culture. e All intraoperative ALs were completely sealed by transplanted DFSs (white rectangle). f Patient chest CT at one month post-surgery showing no observable air space

\section{ACKNOWLEDGEMENTS}

This work was supported by the Research Project for Practical Applications of Regenerative Medicine from Japan Agency for Medical Research and Development (AMED) and had formerly been supported by Creation of innovation centers for advanced interdisciplinary research areas Program in the Project for Developing Innovation Systems "Cell Sheet Tissue Engineering Center (CSTEC)" from the Ministry of Education, Culture, Sports, Science and Technology (MEXT), Japan. We are indebted to Professor David Grainger, University of Utah, for technical review.

\section{AUTHOR CONTRIBUTIONS}

All authors researched, collated, and wrote this paper as a group effort.

\section{ADDITIONAL INFORMATION}

Competing interests: Dr. Masayuki Yamato has equity financial interest in CellSeed, Tokyo, Japan, a publicly traded Japanese biotechnology company exclusively developing cell sheet technology for regenerative medicine purposes. All the other authors declare that they have no competing financial interests.

Publisher's note: Springer Nature remains neutral with regard to jurisdictional claims in published maps and institutional affiliations.

\section{REFERENCES}

1. Gilbert, S. et al. Identifying patients at higher risk of prolonged air leak after lung resection. Ann. Thorac. Surg. 102, 1674-1679 (2016).
2. Loran, D. B., Woodside, K. J., Cerfolio, R. J. \& Zwischenberger, J. B. Predictors of alveolar air leaks. Chest Surg. Clin. N. Am. 12, 477-488 (2002).

3. Attaar, A., et al. A clinical prediction model for prolonged air leak after pulmonary resection. J. Thorac. Cardiovasc. Surg. 153, 690-699.e2 ( 2016).

4. Kanzaki, M. et al. Dynamic sealing of lung air leaks by the transplantation of tissue engineered cell sheets. Biomaterials 28, 4294-4302 (2007).

5. Kanzaki, M. et al. Functional closure of visceral pleural defects by autologous tissue engineered cell sheets. Eur. J Cardiothorac Surg. 34, 864-869 (2008).

(i) Open Access This article is licensed under a Creative Commons Attribution 4.0 International License, which permits use, sharing, adaptation, distribution and reproduction in any medium or format, as long as you give appropriate credit to the original author(s) and the source, provide a link to the Creative Commons license, and indicate if changes were made. The images or other third party material in this article are included in the article's Creative Commons license, unless indicated otherwise in a credit line to the material. If material is not included in the article's Creative Commons license and your intended use is not permitted by statutory regulation or exceeds the permitted use, you will need to obtain permission directly from the copyright holder. To view a copy of this license, visit http://creativecommons. org/licenses/by/4.0/.

(c) The Author(s) 2017 